\title{
A South African Research Institute and Two Theories of Knowledge Production
}

\author{
Alexandra Hofmänner
}

As part of a research project that analyses the role of research in energy policy formulation in South Africa from 1989 to 1998, the institutions that have done energy research during this decade were examined. The Energy \& Development Research Centre(EDRC) has been found to have had a significant influence on national energy research and energy policy formulation during this period, although the Centre employs around twenty researchers only. The origin and organisational history of thisinstitute, its ways of networking and partnering reveal interesting patterns not conventionally associated with the activity of undertaking research. Therefore, the EDRC offers an interesting casestudy by which to probe institutional developments in the domain of current research and knowledge production, which is widely recognised as being in a period of transition.

After providing some general information on the South African context out of which the EDRC originated and within which it conducted its research, I would like to briefly describethe EDRC, its activities, objectives and organisation. Then the two theories of the Triple Helix and Mode 2 Knowledge Production are scrutinised by relating them to the EDRC's experience. The principal features that escape the conceptual structures of the models are then characterised.

\section{The Case Study:The EDRC -}

\section{A South African Research Institute}

The South African Context

South Africa has undergone an internationally un precedented peaceful transition from Apartheid to democracy in 1994. The country's economic, social and political institutions were designed during almost 50 years of Apartheid policy, which systematised discrimination against the majority of the populace, and are now being restructured to meet new policy priorities. These priori- 
ties seek to address the disastrous level of structural inequality and poverty that was sustained under the previous political system.

The circumstances of the South African political economy are mirrored in the country's patterns of energy use. In 1993, despite a significant overcapacity of the national electricity grid, two thirds of households did not have access to electricity (Van Horen et al., 1993). The energy sector has been challenged with the task of transforming industries and creating a fresh system of governance to address a range of problems. The role and performance of bodies and agents of research in this task of urgent transformation are of especial interest with regard to theories which seek better understanding of therelations between the institutional domains - university, industry and government - in the social and economic development process.

\section{The Energy \& Development Research Centre EDRC}

The EDRC was founded at the University of Cape Town in 1989. It is a transdisciplinary research institution committed to producing knowledge which will result in improved policy-making and practical implementation in theenergy sector in Africa (Eberhard, 1998). Work is undertaken in three main areas, that are consolidated in research programmes: 'Energy, Poverty and Development', 'Energy, Efficiency and Environment', and 'Energy, Markets and Governance'. The EDRC offers postgraduate education and training programmes. Research projects are set up proactively: each research programme annually formulates a detailed strategic plan which spells out the vision and mission of the programme, and an analysis of the best fit between sector needs, funding and the EDRC's own commitments and skill base (Energy \& Development Research Centre, 1998).

Although located at the University of Cape Town, the Centre's financial sources were initially drawn from a government coregrant, butit quickly moved to beingfunded by international donors and increasingly national, regional and international contract research. The Centre has established a wide range of partnerships and networks, which reflects in the Centre's variety in kinds of research. During the decade of its existence the EDRC has been challenged by a changing and unsteady research environment. The political transition to democracy was accompanied by profound socio-economic instabilities. Within these circumstances the EDRC undertook research for various agencies, including government, NGOs, civic organisations, labour and industry and international agencies. ${ }^{1}$ During these years of transition the EDRC played an important role in raising issues to the policy agenda, and at the sametime providing support to various agencies trying to address these issues.

The EDRC can be understood to have evolved as an innovative balancing act between a number of constraining and favourable conditions (Hofmänner, 1999). Four features are listed here in an attempt to broadly characterise the innovativemomentum of theorganisation in devising an institutional infrastructure capable of making significant contributions within the multi-faceted energy problems of South Africa. 
- The EDRC is committed to making a difference by improving social equity in the energy sector. It created innovativeinstitutional spaceand devised its own interdisciplinary conceptual setting to realise its objectives.

- The EDRC has rapidly and strategically responded to an unstable external and internal environment. To manage and accommodate these changes the EDRC was required to undergo constant organisational restructuring.

- The EDRC's composition of funding sources soon shifted from government funding to contract research and grant funding. This financial independence from government enabled it to position itself strategically in relation to political developments.

- The EDRC wove a web of networks and partnerships in the energy sector and during this process built a reputation of providing leading-edge research.

\section{The EDRC and \\ Mode 2 Knowledge Production}

The central thesis of Mode 2 Knowledge Production contends that the way in which knowledge is being produced is changing (Gibbons et al., 1994). It identifies a number of attributes that support this thesis. These attributes are examined here for the case of the EDRC. ${ }^{2}$ Mode 2 Knowledge Production is understood as an outgrowth of Mode 1, supplementing conventional ways of producing knowledge. TheEDRC can bedescribed as an outgrowth of Mode $1 .{ }^{3}$ It is consequently a candidate to qualify as operating in Mode 2; the aim of the following paragraphs is to test to what ex- tent this classification is suitable.

Attributes of knowledge production in Mode 2

Knowledge produced in the context of application

This attributeis strongly reflected in the experience of the EDRC. The Centre positioned itself as a separate research institution not bound to a particular discipline of knowledgethrough identifying relevant problems and devising institutional space and capacity to address these. The organisation's mission to undertake relevant research has been a consistent imperative in its objectives over the years. Ultimately, this compels the EDRC to continuously respond to its changing environment. ${ }^{4} \mathrm{As}$ a result, the internal structure of the organisation was revised and adapted continually. $\mathrm{Re}$ search is undertaken by interaction with various stakeholders in the energy sector and results disseminated again in a context of application comprising community organisations, industry, government, academia, NGOs and others.

Transdisciplinarity

The EDRC addressed the need to widen access to energy services for the rural and urban poor in 1992 by launching a national project based on the theoretical framework of Integrated Energy Planning (IEP). A team of researchers from various disciplines was assembled to apply this new analytical planning concept to theSouth African energy situation. The skills required for such a task spanned a wide range of expertise and competence. The 2-year project instigated changes in the EDRC's organisation to accommodate the processes and 
research methodologies that were necessary for the research. The temporary employment of these researchers also initiated the building of a network of associates and partners, still a major resource of the Centre's research capacity.

Heterogeneity of skills and organisational diversity

A number of research programmes group the Centre's research activities in separate domains. The researchers within these divisionsannually design a strategic vision that guides the composition of their research proposals. The organisation of the teams changes constantly within this renewed mapping out of strategies; in-house capacity for research projects is understood as a fluid resource in need of continual adjustment to the problem context in which research is seen as necessary and interesting.

More than one hundred researchers have worked at the EDRC over the past 10 years, while the Centre on average employs around 20 researchers. The organisation of research is therefore institutionalised in an impermanent manner and research is undertaken by temporary teams extendingacrossinstitutional boundaries if necessary. As such the Centre is a pioneering research institute in the South African energy scene and has opened up a new intellectual and institutional territory for the provision of knowledgerelevant to energy problems.

\section{Social accountability and reflexivity}

This attribute has guided the overall research objectives of the EDRC and has certainly directed its choice of research questions within the energy sector. However, this has taken place within an un- derstanding of the term 'social accountability' that does not correspond to the meaning given to it by Gibbonset al. 'Social accountability' carries the imprints of a distinct social, cultural and historical setting.

In South Africa, the expression 'social accountability' must be understood against a heritage of almost half a century of apartheid governance. One of the principal determinants in shaping the local meaning of this expression will therefore relateto racial and cultural inequalities, as expressed, for example, in the lack of energy service provision to the majority of the South African population prior to 1994.

So, the extension of accountability into society can partly be defined across the dividing spheres of public/laypersons versus scientists/ experts (as outlined in the model of Gibbons et al.), but also across racial and cultural demarcations that have hitherto regulated access to thedecision-making processes involved in the research enterprise. Further, the notion of a 'public' presents somedifficulties; as will beshown in the following paragraph. Consequently, the emerging structures and mechanisms within which an expansion of social accountability is articulated, are different. In the case of the EDRC, the tendency of expanding social representation in energy research was expressed in broadening conventional methodologies and practices, in increasingthe emphasis on the dissemination of research results, and in incorporating marginalised groups into the Centre's research capacity.

\section{Quality control}

The written output of the EDRC clearly 
suggests that publication in journals does not receivepriority attention in the dissemination of its research. The Centre's patterns of communication show a variety of channels of interaction with stakeholders in the energy sector, including conferences, workshops, papers, research reports, manuals, education and training programmes, briefings and informal capacity building. Theconventional peer review system of Mode 1 therefore only serves as a limited device in quality control for the research of the EDRC.

For the case of Mode 2, Gibbons et al. identify further criteria by which to control research quality. These emerge from the additional questions that arise from the increasing public demand for social accountability. But the dynamics underlying what is understood as social accountability are contextually sensitive, so too are the emerging questions and their ability to exercise a control function.

For the South African context three characteristics seem decisivein shaping this background. First, the measures for quality control need to besensitiveto the particular social concerns regardingthe issue of extended representation, as described under the previous attribute (context of application). Second, thereis limited capacity and intellectual resources that can bespared to devise and exercise an academic control function, given theurgent and manifold problems which facethecountry. Third, thenotion of a 'public' and its engagement in debating and shaping the policy agenda carries the marks of South Africa's specific political structure and its history. Historical developments have left the country confronted with cultural and racial differences, but also with enormous contrasts in class, education and access to information. The 'public' as used by Gibbons et al. may not incorporatetheoften deeply heterogeneous and unjust conditions prevailing in societies that have endured phases of 'colonial' domination.

\section{Disparities, coherences and problems}

The coherence of Mode 2 is argued principally by means of theaboveattributes. In general, these categories seem to broadly correspond to key features of the EDRC's experience, although the examination indicates that the interpretation of the last two attributes may need modifications.

What are the causes of these variances?Thecore of thetheory of Gibbons etal. suggests theroots of thearisingtension that instigates theemergence of the new mode of knowledge production to liein the parallel expansion of changing conditions on both a supply and a demand side: the number of potential knowledge producers on thesupply side, and the expansion of therequirement of specialist knowledge on the demand side (Gibbons et al., 1994). However, most countries arefar from keeping sustainable mechanisms that even vaguely approach attaining a balance between these two sides. Hence, this hypothesis only holds for specific contexts, namely, environments that are provided with a heritage of well-established research infrastructures and financial resources.

As a result, the proposed theoretical implications of M ode 2 cannot be commensurate with the context of many countries. This becomes particularly clear for two implications that are dis- 
tinguished in the theory of Mode 2: massification of research and increase of research sites and distribution of knowledge across the social spectrum. Providing and maintaining an education system is typically one of thekey challenges on the policy agenda in countries with limited resources. Further, there are obstacles in the field of media and access to information. The EDRC has made a contribution through its postgraduate and training programmes as well as in its efforts to disseminateresearch results within the energy sector of South Africa. But although this may be regarded as a catalyst for both the above listed implications of Mode 2, the relative proportion of the contribution is not sufficient to confirm atrend in this direction in the sense outlined by Gibbons et al.

Therefore, it is argued that, for the case of the EDRC, the difference in content of the attributes is principally due to the difference in key drivers that create the conditions for the emergence of a new mode of knowledge production. Since Mode 2, as an outgrowth of Mode 1 , is understood to display an own set of cognitive and social norms (determining what shall count as significant problems, who shall be allowed to undertake research and what constitutes good science), the differences in the conditions which bring forth the new mode have profound implications.

From this perspective, the utilisation of digits as a means to represent difference may be somewhat misleading: Mode 1 is itself an outgrowth of a particular context of a social episteme. ${ }^{5}$ These unspoken historical and social roots that condition the knowledge enterprise become important when this model is transferred to non-industrial- ised countries, especially those that have experienced forces of colonialisation in the realm of knowledge. The infrastructure of knowledge institutions in these countries has a social heritage based soundly in the political struggle thathas shaped their development. More research on the attributes that drive the emerging new knowledge in these situations is required, since they represent the arena in which efforts in research and knowledge are most urgently needed.

\section{The EDRC and the Triple Helix Model}

The EDRC conducted its research during a period in which the control of the South African state over institutional spheres was loosened and its involvement in the interactions between them changed. In the vocabulary of the Triple Helix Model, South Africa's energy sector may be regarded as in transition from a Triple Helix I configuration in which

the state encompasses academia and industry and directs relations between them (Etzkowitz and Leydesdorff, 1999).

The EDRC can bemapped into the configuration of Triple Helix III which generates

a knowledge infrastructure in terms of overlapping institutional spheres, with each taking the role of the other and with hybrid organisations emerging at the interfaces (Etzkowitz \& Leydesdorff, 1999).

The research activities of the EDRC certainly cross conventional boundaries in the institutional organisation of energy research in South Africa. Since one purpose of the Triple Helix model is to 'ex- 
plain phenomena' that are analysed by other authors as an attempt to describe the change in knowledge production (Etzkowitz \& Leydesdorff, 1999), these institutional spheres need to be probed for specific cases that emerge within these changes. TheEDRC has interacted and worked with all three spheres identified in theTripleHelixmodel. However, some of the EDRC's institutional partners and clients do not fall into any of these categories. An attempt will be made to cluster these into groups that together make up a fourth hybrid institutional sphere. The intention of forming this additional sphere is not to suggest complementing the model in this manner, but to portray these institutional partners and clients in direct relation to the theory.

\section{Institutional spheres}

Academia: The EDRC has co-operated with a number of South African and international Universities. Interaction takes place in form of joint research projects, co-authoring of papers, internships, and educational training. The Centre's relationship to the University of Cape Town has changed alongside the organisation's strategic internal and external restructuring as a response to a changing research environment.

Industry: The new democratic South Africa has inherited an energy industry that was largely state-controlled. Theinteractions with academic research institutions (designed and managed within almost 50 years of Apartheid) happened within clear separation of the different Triple Helix spheres. This arrangement sustained and reinforced an understanding of the energy sector that ne- glected the energy service provision of two thirds of the population.

During the process of bringing the pressing problems of the household level to the energy policy agenda the EDRC established contactsand relationships with Eskom, the national electricity utility. The EDRC's 2 year national policy research programme paved one way to the identification of electrification of rural areas as an immediate priority of the new government. Itthen provided research and capacity building to accompany this process. Eskom, as the single national utility in charge of generation, transmission, and largely also distribution of electricity, was necessarily involved in the process of addressing this challenge.

The primary focus on these shortterm research priorities may be one of the reasons that no direct research interactions were established with other state corporations in the energy industry (for examplethe Atomic Energy Corporation, Sasol). Other reasons may be found among the specific problems in the constitution and strategic mission of theseindustries during the years of transition.

Government: Governmentagencies have been a major reci pient of the EDRC's research. The communication of this research has taken place through a variety of activities: capacity building, reports, briefings, conferences, workshops, research reports, handbooks, training and seminars. The EDRC was strongly involved in the process of developing a White Paper on Energy Policy of South Africa. ${ }^{6}$ But such research partnerships with 'government' only began after the 1994 elections, although research had been undertaken for the Department of 
Minerals and Energy previously. The EDRC also conducted research for political organisations outsidethereal $m$ of 'government' that had a significant impact on the energy policy agenda of the post-apartheid South Africa (seebelow).

Other: A range of EDRC partnerships cannot be easily mapped into the above two spheres. They will be grouped here into three institutional domains of civil society. The first are non-governmental organisations. NGOs comprise a variety of types of organisations, ranging from political to environmental groups. Organisations of this kind have been important partners, donors and clients of the EDRC. The second group is unions. The EDRC conducted studies for different divisions of the Congress of South African Trade Unions COSATU (for example the National Union of Metal Workers, the National Union of Municipal Workers, the Chemical Workers and Industrial Union). The third domain is not easily classified, since it contains temporary political groupings which, however, can neither be assigned to the sphere of government nor categorised as NGOs. Examples are the National Electrification Forum (NELF), a temporary body that would set up the National Electricity Regulator of the newly democratic government, or the Science and Technology Working Group of the African National Congress, that prepared the S\&T policy priorities of the ANC in preparation of the change of government in 1994.

To summarise, the Triple Helixmodel is based upon the premise that

The dimensions of government, industry, and higher education tend to be reproduced because they continue to serve different functions. The institu- tions embody the value systems or the codes of these functions. (Leydesdorff \& Etzkowitz, 1998).

From the results of the above examination, in which certain institutional realms were found to be non-represented within the spheres mapped out in the Triple Helix, it may be deduced that the view of a distinct and steady functionality of institutions is not valid for all cases. Apart from the case of unions, the institutions that escape the model's conceptual framework tend to be either short-lived or temporary in their mission and purpose or are more oriented towards creating institutional space for immediate needs in the medium term, rather than constructing an organisation that is to hold through time. So the model falls into a pitfall of cyclical logic: although it relies on emergence as a concept to understand institutional change with time, its partitioning into three distinct spheres restricts the accommodation of emergent institutional phenomena into these categories.

Disparities, coherences and problems

What are the causes for the absence of these institutional spheres within the model? To approach this question it seems appropriate to examine the purpose of constructing the three dimensions of industry, government and university as a basis for a model on knowledge production. These institutional spheres are used as the basis on which then a theory of communication is instated that combines viewsfrom complexity theory and sociological systems theory; 
The capacity of relevant participants to handle the complexity of the implied communications, is then the evolving unit (Leydesdorff, 2000).

To examine themodel'sapplicability and use for a case study such as the EDRC it thus seems necessary to investigate the above question by applying the system of vocabulary from this amal gamated theoretical backbone of common theory that creates a particular flow of logic. It is also necessary to look at the basic assumptions upon which these two theories rest, since they will be carried over to some extent into the new blend of vocabulary.

Applying certain concepts from systems theory and evolutionary theory to sociology is argued to deliver the solution of the reflexivity issue (Leydesdorff, 2000 ) through the idea of a metabiological perspective. This theory replaces the metaphysical quest for last causes and foundational origins with a (potentially empirical) focus on emerging order (Leydesdorff, 2000).

This results in a robust framework of definitions, processes and relationships. The robustness is mainly due to the underlying geometrical imagery that is used to represent the model. The EDRC can be probed by thinking along these lines, and certain elements and processes can be found to correspond with the theory. For example, the EDRC may be regarded as a multi-layered network system, that at each moment represents both a network of events and a network of perceptions of these events.

But the model's analytical robustness has costs at other levels, and these may give indications to the question of how the above institutional spheres came to beneglected in thetheory. First, its com- plexity would require an unrealistic amount of information and work to gain an understanding of the actual research process. Second, by using a system of reference of clearly defined concepts and inflexible constructs, ambiguous and indistinct issues are neglected. For instance, by defining an institutional sphere in terms of the noun 'government', the more vaguely emboundering realm of 'politics' is avoided. Further, although the model theoretically accommodates the terms 'randomness' and 'historicity' in practice it is not possible to clearly defineboundaries between the two in retrospect. Likewise, it must be questioned to what extent the abstraction of human communication as represented by two layers selecting upon each other (Leydesdorff, 1997) (human action being both reflexive and hyperreflexive) can serveto better understand decision-making processes and choices.

It is possible to insert the EDRC into the model of communication of the Triple Helix. The relevant question for this conference, however, is to what extent this can serve as a basis for understanding better the actual approaches and problems in the activity of undertaking research, especially with regard to the theme of this conference that is dedicated to the social and economic development process. For example, the EDRC's involvement in the development of a White Paper for Energy Policy for South Africa happened at what may be referred to as a process with different levels and recursions in the Model of the Triple Helix. But such a description would fail to capture the momentum that drove the process, since its meaning is not readily reduced into a word such as strategy or mission. This mo- 
mentum is related to the indeterminate realms of culture, meaning and values that by their nature evade uniform categorisation.

In terms of communication, themodel rests upon two assumptions that cannot beconfirmed empirically by means of the casestudy of theEDRC. The firstassumption is that knowledge flows via communication between institutional spheres. ${ }^{7}$ The second assumption is that these processes can be reconstructed. Empirically, it is not possible to trace the flow of the EDRC's produced knowledge among institutional spheres. Therefore, the case study does not allow the conclusion that communication among institutional spheres is the principal agency in the streamsand whirls of knowledge. Further, communication is a culturally sensitive activity that is notnecessarilyunderstood mainly by means of a system of interaction. It may beargued that thereareother means of creating, acquiring and disseminating knowledge, which give more emphasis to the form and manner of interaction and co-operation rather than to theindividual (linear or non-linear) processes of communication. ${ }^{8}$

The casestudy on theEDRC therefore confers a theoretical discord in both the trinity of spheres and the theory of communication that is imposed on it. The trinity of spheresclearly was designed for a particular context that assumes driving forces that are not universally applicable. This difficulty could behandled in two ways. Either the additional institutions are grouped into a fourth sphere, containing 'anomalies'. This, however, would mean that a rigid normative framework would be established in theory, that originatesin and principally onlyaccountsfor contextsamong which institutional realms of society are comparatively similar and not diverse. Further, the problem would beleft unsolved of whether the quite limited concept of 'government' is not overweighed relative to other political realms that would be placed into a conceptual melting pot in the fourth sphere. Another possibility would be to redefine the institutional spheres to better correspond to contextual differences. This would include, for example, thecircumstancesin countries in transition which are designing their own form of democratic understanding, and countries that are faced with critical and urgent socio-economic problems. The difficulties encountered in the theory of communication that is applied to the three spheres may appear in any case study that utilises the model, since they give accent to the limits of models to better understand social dynamics.

Despite these problems, the Triple Helix Model, on a whole, captures three of the four features given at the beginning of the paper that characterise the EDRC's experience of devising new infrastructure for research and knowledge. The first feature, a 'commitment to making a difference' defies the conceptual framework of the model.

\section{Conclusion}

This paper analyses the EDRC, a South African research institution, from the point of view of two theories regarding changes in knowledge production. The resulting two profiles cannot be compared and evaluated directly, since they represent two different systems of reference that are conceptually incommensurate because of the scaffold of definitions that is constructed around them. 
Nevertheless, their parallel analysis of a particular case study such as the EDRC, together with an unearthing of their respective basic assumptions, can serveto reveal areas that are disregarded in the models.

By means of a research institution situated in Africa that is concerned with energy and development, it has been shown that the dynamics of knowledge production within this particular context cannot be understood through the two models only. The African context is characterised by having to address a different set and magnitude of social and economic problems. These different conditions have repercussions at the level of the basic assumptions on which the two models rest. Yet, the models can be used concurrently to discern additional issues that must be taken into consideration in these situations. In this way they may provide insights into the practical processes around institutional dynamics and innovation in knowledge production that may result in a better understanding and tackling of the challenges in thesocial and economic development process.

\section{Notes}

1 Sponsors and clients of the EDRC include: the World Bank, the UNDP, the European Union, the Canadian International Development Research Centre, development assistance agencies from Canada (CIDA), Norway (NORAD) and the Netherlands (DGIS), the Southern African Development Community, governments of $\mathrm{Na}$ mibia, Botswana, Swaziland, Mozambique and South Africa, the South African Department of Minerals and Energy, Eskom, the Development Bank of South Africa, and various private and civil organisations, including unions.
2 The expression knowledge production is used in both theories that are analysed here for the case of the EDRC. It is not the theme of this paper to test the suitability of using theterm 'production' in conjunction with knowledge for the research undertaken at the EDRC. The term will be adapted as an unverified hypothesis for the scope of this paper. Nevertheless, it is critical to remark that the usage of 'production' holds an undercurrent of farreaching assumptions. The results of the following analysis indicate that these assumptions must be made explicit and handled cautiously when moving the expression between contexts.

3 Initially theEDRC was attached to theEnergy Research Institute in the Faculty of Engineering at the University of Cape Town. It soon changed its name from 'Centre for Research into Appropriate Technology (CRAET)' and attained the status of a separate research centre within the Faculty.

4 The EDRC commits itself to 'seek improved social equity in the energy sector and for this issue to be placed on the top of theenergy policy agenda' (Energy \& Development Research Centre, 1998), through:

- undertaking research to deepen knowledge and understanding of the energy needs, problems and challenges in South Africa, and therest of Africa, and innovative ways of responding to these;

- contributing to transformation and improved social equity, economic efficiency and environmental sustainability in the energy sector through public-interest advocacy and through communicating knowledgeand understanding it as a resource for better policy-making and implementation

- educating, training and developing human resources in the energy field

5 Thisoutgrowth need not befounded in an understanding of knowledge as geared towards production, and I would argue that even Mode 1 is more geared toward fabrication than towards production, and that our understanding of it as an activity 
contributing to 'production' is both a result and in itself evidence for the shift in our understanding of knowledge that is more related to economic innovation.

6 During the years after the 1994 elections government departments followed a mandate to Cabinet and Parliament to review all public policies and to develop new policy imperatives by developing White Papers and new legislation to provide the policy frameworks within which both the public and private sector could operate.

7 The dissemination of knowledge into poor rural and urban communities has been an important challengeto theEDRC. This domain of society is typically not represented in established institutional spheres. Further, this domain does not exist in somecountries, which may partly account for their 'value systems' not being reproduced in the institutional spheres identified by Leydesdorff and Etzkowitz (see last quotation).

8 Thephenomenon of leadership may serve as a thought experiment to illustrate the point.

\section{References}

Eberhard, A. \& Van Horen, C.

1995 Poverty and Power: Energy and the South African State. London: Pluto Press.

Eberhard, A.

1998 "Strategic, knowledge-based partnering and networking for capacity building in the energy sector: SomeAfrican experiences and lessons." Prepared for the United Nations Commission on Science and Technology for Development (Working Group on Science and Technology for Partnerships and Networking for National Capacity Building), Malta, 28-30 September.

Energy \& Development Research Centre

1998 EDRC Report 1997-1998. Rondebosch: University of Cape Town.

Etzkowitz, H. and Leydesdorff, L.

1999 “WhoseTripleHelix?" Scienceand Public Policy 26, 4: 138-139.
Gibbons, M., Limoges, C., Nowotny, H.,

Schwartzman, S., Scott, P., and Trow, M.

1994 The New Production of Knowledge: The Dynamics of Scienceand Research in Contemporary Societies. London: Sage.

Hofmänner, A.

1999 An Anthology of Research: The first 10 Years of the Energy \& Development Research Centre. Cape Town: Fingerprint Publications.

Leydesdorff, L.

1997 "The New Communication Regime of University-Industry-Government Relations." Pp 106-117 in Etzkowitz, E. and Leydesdorff, L. (eds.) Universities and the Global Knowledge Economy: ATriple Helix of University-Industry-Government Relations. London, Cassell.

2000 "Luhmann, Habermas, and theTheory of Communication." Systems Research and Behavioural Science 17, 3: 273-288.

Leydesdorff, L. and Etzkowitz, $\mathrm{H}$.

1998 "The Triple Helix as a Model for Innovation Studies." Science and Public Policy 25, 3: 195-203.

Munasinghe, $M$.

1990 Energy Analysis and Policy. London, Butterworths.

Nowotny, $\mathrm{H}$.

1990 In Search of Usable Knowledge. Utilization Contexts and the Application of Knowledge. Muenchen, Campus Verlag.

Van Horen, C., Eberhard, A., Trollip, H., and Thorne, S.

1993 "Energy, environment and urban poverty in South Africa." Energy Policy 21, 5: 623-639.

\footnotetext{
Alexandra Hofmänner

Collegium Helveticum

Swiss Federal Institute for Technology

(ETH), Zürich, Switzerland

and

Energy\& Development Research Centre,

Cape Town, South Africa
} 